Important Difference (MCID) of 0.5 was applied to determine clinical significance.

Results Patients with advanced COPD scored lower across all four CRQ domains. This was statistically significant for the dyspnoea, mastery, and emotional functioning scores $(p<0.05)$, and clinically significant for latter two, suggesting poorer respiratory HRQoL (Table 1).

Conclusions Patients with breathlessness due to advanced COPD had worse respiratory HRQoL than those due to advanced cancer. There are three potential explanations for this finding: (1) there may be a greater burden of breathlessness in COPD due to condition-longevity, (2) the burden of breathlessness may be less in cancer due to the episodic nature of the symptom in malignant conditions, and (3) it may reflect variance in palliative referral thresholds by disease group. Our results further suggest that greater access to palliative care is needed in advanced COPD and that formal psychometric testing of the CRQ may be warranted in cancer.

\begin{tabular}{|c|c|c|c|c|c|c|}
\hline \multicolumn{7}{|c|}{$\begin{array}{l}\text { Abstract M5 Table } 1 \\
\text { with associated } p \text { values }\end{array}$} \\
\hline $\begin{array}{l}\text { CRQ } \\
\text { Domain }\end{array}$ & $\begin{array}{l}\text { Advanced } \\
\text { Diagnostic } \\
\text { Group }\end{array}$ & Median & $\begin{array}{l}75^{\text {th }}-25^{\text {th }} \\
\text { Percentiles }\end{array}$ & Mean & $\begin{array}{l}\text { Standard } \\
\text { deviation }\end{array}$ & $\begin{array}{l}\text { P value from } \\
\text { Independent- } \\
\text { Samples Mann- } \\
\text { Whitney U Test }\end{array}$ \\
\hline \multirow[t]{2}{*}{ Mastery } & COPD & 3.75 & $4.75-2.75$ & 3.81 & 1.28 & $0.001^{*}$ \\
\hline & Cancer & 4.50 & $5.50-1.75$ & 4.52 & 1.22 & \\
\hline \multirow[t]{2}{*}{ Dyspnoea } & COPD & 3.00 & $3.60-2.40$ & 3.02 & 0.93 & $0.038^{*}$ \\
\hline & Cancer & 3.50 & $4.00-2.60$ & 3.41 & 0.98 & \\
\hline \multirow[t]{2}{*}{ Fatigue } & COPD & 2.88 & $3.75-2.00$ & 2.97 & 1.13 & 0.126 \\
\hline & Cancer & 3.25 & $4.19-2.25$ & 3.29 & 1.20 & \\
\hline Emotional & COPD & 3.86 & $4.33-3.11$ & 3.84 & 1.13 & $0.004^{*}$ \\
\hline Function & Cancer & 4.50 & $5.14-3.57$ & 4.35 & 1.06 & \\
\hline
\end{tabular}

\section{M6 CAN CLINICAL PSYCHOLOGY INPUT IMPROVE CARE QUALITY AND REDUCE ADMISSIONS AMONG PATIENTS WITH RESPIRATORY DISEASE?}

G Thew, J MacCallam, J Robinson, P Salkovskis, J Suntharalingam. Royal United Hospitals NHS Foundation Trust, Bath, UK

\subsection{6/thoraxjn-2015-207770.433}

Introduction and objectives Health outcomes for patients with respiratory conditions can be significantly affected by their psychological wellbeing; those experiencing psychological difficulties are less able to manage symptoms, have a poorer quality of life, and have more frequent hospital admissions. National guidance recommends the need for the assessment and treatment of psychological difficulties secondary to respiratory disease, but implementation of this across services is inconsistent. Here, we report the findings of a nine-month trial integrating clinical psychology into a specialist respiratory department, which aimed to identify the psychological needs within this patient group, provide interventions to address these needs, and to evaluate the impact of this across a range of outcome domains.

Methods Standardised measures were used at two timepoints to assess levels of common psychological difficulties among inpatients. Psychological assessment and intervention was implemented as clinically appropriate within the context of the wider multidisciplinary team. This addressed issues including breathlessness-related panic and anxiety, low mood, health concerns, self-management of illness, coping strategies, and supporting discharge. Data on hospital admissions were used to evaluate changes in healthcare use following intervention. Feedback was collected from both patients and staff to review the experience and acceptability of psychology provision.

Results Results showed that the rates of clinically significant symptoms of depression, anxiety, and health anxiety among inpatients were $71 \%, 40 \%$, and $21 \%$ respectively. They highlighted that integrating clinical psychology into the multidisciplinary team was received well by patients and staff, leading to improved patient experiences and clinical outcomes, and a greater focus on holistic care. Of the 69 patients receiving psychology input with at least one month follow-up data, 77\% showed a reduction in their admission frequency, and those readmitted showed an average reduction in length of stay of 1.7 days. The associated cost savings to the wider NHS more than covered the costs of providing psychology input.

Conclusions In light of existing literature, national guidance, and the present findings, we highlight the need for those commissioning and managing respiratory services to consider the varied benefits of integrating psychological provision for a patient group with high levels of psychological need.

\section{M7 LEADING FOR IMPROVEMENT - AN ESSENTIAL INGREDIENT IN QUALITY PATIENT CARE: A RESPIRATORY EXPERIENCE}

S Kumar, M Gittus, A Cracknell, SDW Miller. Leeds Teaching Hospitals NHS Trust, Leeds, UK

\subsection{6/thoraxjn-2015-207770.434}

Background and objectives Many respiratory patients have deranged physiology and can deteriorate rapidly during acute episodes. Consequently, early decision-making is vital to improve outcomes and to ensure patient's wishes are respected.

We aim to improve the care of inpatients who acutely deteriorate through clinical leadership, as part of a quality improvement (QI) collaboration, by improving early decision-making and clinical response.

As a pilot project we retrospectively (January 2012-September 2014) analysed all 2222 calls from three respiratory wards (84 beds). Fewer events occurred at the weekend (9.4\% per day) compared to weekdays (16.2\% per day). More events occurred between 0900-1700 (41.1\%) compared to out of hours (58.9\%). Decision-making was found to be poor with $12.2 \%$ patients having cardiopulmonary resuscitation (CPR) decisions in place.

Methods Following initial data analysis, one ward participated in a QI project to identify areas for improvement and target these through small tests of change. The interventions implemented by the ward team included a staff survey, "deteriorating patient stamp", post-2222 call debriefing and "safety huddles". The effectiveness of these interventions was measured through analysis of on-going arrest calls and documentation of decision-making in case-notes.

Results Reduction in number of 2222 calls on pilot ward between pre-intervention and post-intervention time periods (mean 1.44 vs. 0.56 ) as shown in Figure 1.

Total 2222 calls per bed reduced for the pilot ward $(63.6 \%$ reduction) compared to non-pilot wards (9.68\% increase) during the pre and post-intervention phases. Similar results were shown for cardiac arrests alone $(62.5 \%$ reduction compared to $26.7 \%$ increase). Decision-making was improved through the 